\title{
Leadership management needs in evolving biotech companies
}

Andreas Föller outlines the different management skills needed by growing biotechnology companies.
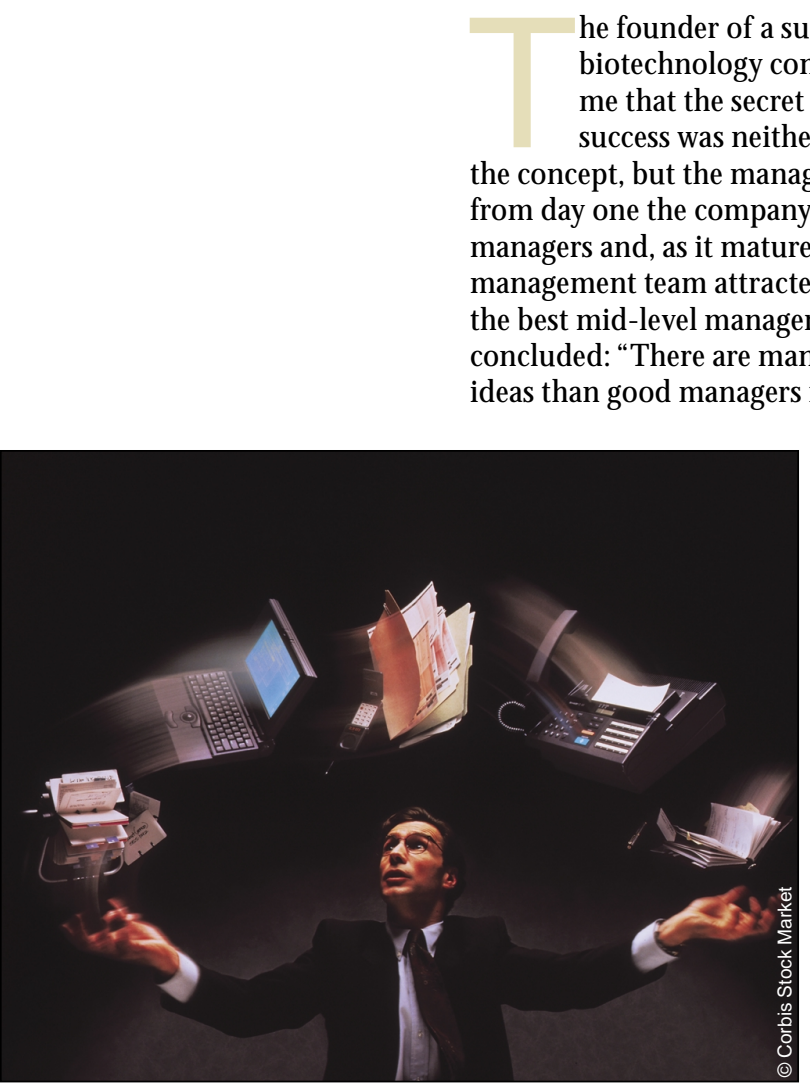

ate the effect of management.

So, when it comes to the biotechnology industry, what is the definition of a good manager? In principle, we believe that there are three sets of qualities that need to be taken into account:

- General traits that apply to good managers of all companies in all industries - Attributes that are particularly important in managers of biotechnology startups

- Experience that matches the company's

Andreas Föller is senior partner in thelife science IT practicegroup at Heidrick \& Struggles (M unich), a leading consultancy in executive search (afoeller@heidrick.com). particular stage of development.

\section{Qualities of good managers}

A good manager will have the personality traits of a leader. Among other things, he or she will have a high degree of personal integrity and will be energetic, goal-oriented, fact-oriented, highly achieving, socially competent and aware of group dynamics, charismatic, able to motivate people, and reliable.

\section{Qualities of good biotech startup managers}

The challenge for the manager of a biotechnology startup, especially in Europe, is to foster a transition within the founding team from science-oriented to commerce-oriented thinking and action.

An academic scientist's focus is on scientific publications, intellectual brilliance, research involving tightly circumscribed projects, and science for science's sake. A biotechnology company, however, must translate research results into revenue, and the management team of a biotechnology company will be judged by investors on the number, size, and importance of the deals that they make and on how they interact with all parties involved (investors, scientific advisors, potential partners in big pharmaceutical companies, medical opinion leaders, public authorities, the press, and so on), how successfully they create an operational company, and how they react to change and deal with pressure- all of which can be extremely grueling. For example, it takes more mental strength and stamina than most people might imagine to remain friendly, optimistic, and self-confident while at the same time desperately trying to raise money and having to answer the same, often uninformed, questions repeatedly from potential investors.

Because they need to be everything to everyone, it is particularly important that biotechnology managers possess the following characteristics:

They must be strong yet sensitive to their environment. Only managers with excellent interpersonal skills will be able to handle sensitively such delicate tasks as 
helping the company founders think commercially and training them in what to say where and when, deciding to cancel a pet project, bringing in and integrating new employees better paid than founding staff, and introducing formal management tools such as reporting and budgeting - all without damaging employee relations. They must combine strategic thinking with a can-do mentality. While a company is in its early stages, with few employees, a manager must assume many roles. While acting as a visionary and developing innovative business plans and "big-picture" strategies, managers are still very operational and must have a hands-on attitude- being willing to put together the information for a presentation and to prepare one's own slides, for example.

They must be highly motivated and aware of the challenges ahead. A successful biotechnology manager must know what to expect during the early stages of a startup and be eager to fight to overcome obstacles. O ur experience tells us, for example, that candidates who are looking to manage a biotechnology firm merely to try something different from big pharma are likely to be unsuccessful. To succeed as a biotechnology chief executive officer, one must be passionate not only about a product or technology but also about achievement in general.

\section{Stage-specific management experience}

As a biotechnology company grows and develops, different management skills and experience are required.

Early stage. This is the stage when a scientist has an idea and is just starting to form a company, perhaps with fellow scientists. The company is defining the concept underlying its business plan (for example, a technology platform or drug candidate) and is trying to bring the team together. In this phase, it is crucial to get the prod- uct or technology right, secure the intellectual property and early financing, be very creative in solving problems, and develop market understanding. Thelevel of management sophistication is quite low, with the management team often consisting solely of founders, and is quite internally focused and hands-on; executive managers from outside are not usually perceived as necessary. N everthel ess, even in this phase, a manager can start to feel overwhelmed with demands on his or lenging phases in the development of a biotechnology company. On paper, the organizational structure of the company is still quite simple, but this does not reflect the reality of its day-to-day operation. Unfortunately, we see many companies where all (perhaps 50) staff report directly to a chief executive officer who operates the company rather like a family business in which people are not able to criticize each other and are reluctant to define clear roles and responsibilities. In our experi-

\section{The challenge for the manager of a biotechnology startup, especially in Europe, is to foster a transition within the founding team from science-oriented to commerce-oriented thinking and action.}

\begin{abstract}
her time and energy. This stage usually ends when the company has about 25 employees.
\end{abstract}

Commercialization stage. This is the phase in which a company turns an idea into a business. By the end of this phase, the company will (in Europe) have between 50 and 70 employees and a private market valuation in the upper double-digit million euro range, and it will have proven that it can generate a profit. It is important that the company and its team understand the market and its dynamics; devel op concrete routes for commercializing the product (by choosing the right partners, for instance); always be prepared to alter their strategy in the light of new scientific trends and advances; assure sufficient funding to bring a product to the market; develop a robust business plan; define the first controlling and budgeting processes; and embark on their first business alliances and deals.

In our eyes, this is one of the most chal-

\section{Warning signs}

Various symptoms that indicate that the wrong CEO is in place include:

- There are too few, or too many, internal discussions

- Employees are not proud of their company

- All issues (internal and external) are deferred to the CEO

- If you ask everybody in the company to describe the company's goal in one sentence, either you hear too many differing statements or, worse, people cannot describe its goal at all

- The company suffers several failures in a row

- People stop having fun at work

ence, this is the point at which most companies fail, mostly because they have tried to keep the "warm, friendly, and intimate" feeling from when the company was first established, failing to realize that a shift to professionalism is absolutely essential.

It is in this phase that the first outside hires usually take place, but it is our experience that this is often a case of too little, too late. Though companies in this phase might bring in a vice president for clinical research and business development, or even a chief financial officer, many still think that they do not need an external chief executive officer. However, we believe that the need to implement professional processes, operations, and organizational structures during this phase requires that experienced executive managers be brought in from outside.

O perational stage. At this stage a company is likely to have products in clinical trials. Business strategies become increasingly important, as do revenue and cost management. Keeping promises (to public business partners, investors, and head physicians, for instance) also becomes essential. In this phase, the company needs to demonstrate its marketability by making alliances, deals, and strategic partnerships. Usually, by now, a shift in focus from project to transaction has taken place, and the management team has imposed some hierarchy, defining clear communication channels, roles, and rules. H owever, the management team is under pressure from its responsibility for millions of euros from investors, and perhaps from the expectation of an imminent IPO, 
so a successful executive management team at this stage must be result-oriented, precise, and efficient-characteristics that are moreakin to those of managers in big industry than was true at the earlier stages. If the managers from the previous stage do not grow into this role, they must be replaced by others who do have "big industry" background.

Expansion stage. A company in this phase strives to realize all its promises to investors. At this stage the company is leveraging its previous success and redefining its business, and is well on its way to becoming a public company. At the same time, the company has to fuel its pipeline with new projects and meet the market's expectations. A company in this phase does not have to be fully integrated in terms of research and development, production, sales, and marketing, but it faces a choice in this regard. (i) The company may bring its own products to at least one large market, such as Europe or Japan. In this case the company must be able to compete with giants (unless it targets very small niche markets), and it must hire people with relevant sales and marketing experience. (ii) The company may focus on its own research and development activities, identifying leads, transforming them into products and then, most likely when they are in phase 2 or 3 trials, selling them to other companies. Here, experience in clinical development and project management is necessary.

\section{Conclusions}

To sum up, the roles of the chief executive officer and his or her top management team are particularly crucial for a biotechnology company. Not only do biotechnology companies require managers with unique qualities, but in most cases different qualities - and therefore managersare also needed as the company matures. And if these are not in place, there are often clear warning signs of this lack (see "Warning signs").

And it is here that we see big differences between Europe and the United States. In the United States, people accept more easily that top managers are perhaps suitable only for a certain phase of a company's development. In Europe, by contrast, we see many founders or early-stage managers who insist that they can manage a company no matter how far it develops. Perhaps this is one reason why many companies in Europe have come unstuck and why consolidation is not occurring as fast as predicted. 